\title{
A ARQUEOLOGIA E A POLÍTICA DO ANTI-HUMANISMO
}

\author{
Lara Pimentel Figueira Anastacio ${ }^{1}$
}

Resumo: Trata-se de interpretar a arqueologia como uma prática ao analisá-la como um método que pretende não apenas circunscrever os campos discursivos que tornam possíveis os saberes de cada tempo, mas também definir aquilo que se localiza na fronteira do que é pensável em cada um desses campos. Ao descrever os limites do pensável, torna-se tarefa do arqueólogo também tornar possível o impensável por meio da experiência da diferença. Pretendemos, assim, identificar esse movimento do pensamento foucaultiano, que certa tradição acadêmica identifica como "anti-humanista", ao descrevermos o círculo antropológico que caracteriza a episteme moderna em As palavras e as coisas, a consequente crítica de Foucault a esse problema e sua posterior solução em textos que iniciam seu percurso genealógico.

Palavras-chave: Foucault - arqueologia - prática - representação - humanismo.

A ênfase dada por Foucault à diferença entre ciência e saber é fundamental não apenas para a análise da formação dos dois domínios, mas principalmente para a investigação sobre a perspectiva do filósofo que pratica a arqueologia. A resposta à pergunta "o que é possível saber?", como aponta Foucault em $A$ arqueologia do saber, não depende apenas de uma análise sobre discursos ${ }^{2}$ que são constituídos por conjuntos de enunciados subordinados a leis a partir das quais métodos e resultados comprovam a cientificidade daquilo que é dito. Ao lado desses enunciados acumulados que adquiriram o estatuto de ciência em determinadas circunstâncias há outros elementos que interagem e podem permanecer no espaço e no tempo em decorrência dessa relação, formando uma rede que se sustenta por si em virtude de objetos em comum: enunciados que se delineiam a partir de "modalidades de existência" próprias ${ }^{3}$, que existem sem a necessidade de um sujeito intermediário, e que se contornam por meio de suas "regularidades discursivas". O saber refere-se então ao conjunto de enunciados em torno de um domínio de objetos, discursos aos quais pertencem não somente aquilo que é tomado como ciência, mas que também circulam como enunciados empíricos, ensaios, crenças e opiniões sobre ética, política, literatura, filosofia e qualquer área

\footnotetext{
1 Doutoranda no Departamento de Pós-Graduação em Filosofia da USP. Orientador: Prof. Dr. Pedro Paulo Pimenta. E-mail: larapfa@gmail.com.

${ }^{2} \mathrm{O}$ artigo considera a diferença entre discurso e enunciado apresentado por Foucault no capítulo "A descrição dos enunciados": "Chamaremos enunciado a modalidade de existência própria desse conjunto de signos: modalidade que lhe permite ser algo diferente de uma série de traços, algo diferente de uma sucessão de marcas em uma substância, algo diferente de um objeto qualquer fabricado por um ser humano; modalidade que lhe permite estar em relação com um domínio de objetos, prescrever uma posição definida a todo sujeito possível, estar situado entre outras performances verbais, ser dotado, enfim, de uma materialidade repetível (...) o termo discurso poderá ser fixado: conjunto de enunciados abrangidos por um mesmo sistema de formação; é assim que poderei falar do discurso clínico, do discurso econômico, do discurso da história natural, do discurso psiquiátrico.” (FOUCAULT, L'archéologie du savoir, p. 140-141).

${ }^{3}$ FOUCAULT, L'archéologie du savoir, p. 140. Os textos citados na língua original possuem tradução de nossa autoria.
} 
que, sob a perspectiva da comunidade enunciativa, criam arquivos sobre determinada formação discursiva:

A esse conjunto de elementos, formados de maneira regular por uma prática discursiva e indispensáveis à constituição de uma ciência, embora não sejam necessariamente destinados a lhe dar lugar, pode-se chamar saber ${ }^{4}$.

O influxo desse modo de análise dos discursos marca todo pensamento foucaultiano ulterior e a própria noção de "prática discursiva" será determinante ao dirigi-lo, de um lado, no sentido de delimitar as condições de possibilidade do pensamento, e, de outro, para conseguir exercitar aquilo que ainda é impensável e, assim, se inscrever e remanejar, em um movimento que desconcerta ao relativizar conceitos fundamentados após séculos de humanismo, certa rede de práticas constitutivas do presente.

Ao se afastar da epistemologia ou de uma análise interna da estrutura de uma ciência ${ }^{5}$, o arqueólogo abre espaço para um projeto filosófico que suspende o valor de verdade do seu discurso ao sondar e testar aquilo que se acredita estar na origem de uma região do sujeito de conhecimento, com a condição de sustentar os paradoxos e problemas subsequentes à essa postura inicial. O mapeamento arqueológico daquilo que se tornou um campo de saber em determinados momentos da história possibilitou um pensamento crítico que não apenas se detém sobre os critérios para o surgimento de enunciados a partir das relações estabelecidas e coordenadas entre os próprios enunciados que as formam, mas também considera a possibilidade de um pensamento futuro ainda não elaborado, e, nesse sentido, a análise foucaultiana da instauração das epistemes já se entende como um permanente ato crítico que questiona o solo, que se acreditava bem estruturado, do sujeito fundador do conhecimento.

Como um exercício de descobrimento de territórios pré-conceituais ${ }^{6}$, que subjaz e prefigura nos desenhos das epistemes a forma do saber que só pode ser compreendida a partir desse campo prévio, Foucault demarca, como insiste inúmeras vezes em $A$ arqueologia ${ }^{7}$, da tradição epistemológica da história das ideias, escavando o espaço necessário para um discurso filosófico que se reconhece como prático e que, como buscaremos descrever adiante, não mais distingue o mundo teórico do mundo das práticas discursivas. Para tanto, foi necessário recuar ao campo discursivo ao qual pertence esse sujeito fundador, descrito pejorativamente por Foucault como um "narcisismo transcendental", que ordena e impõe sua lógica contínua à acontecimentos irregulares e dispersos. Herdeiro de um humanismo que se acha alicerçado, desde o início, em uma confiança ilimitada no homem e nas suas

\footnotetext{
${ }^{4}$ FOUCAULT, L'archéologie du savoir, p. 238.

5 “A distinção entre ser ciência ou não é posterior [à arqueologia], obedece a critérios de objetividade e sistematicidade, e tem na existência do saber sua condição de possibilidade. Essa é uma aquisição fundamental da abordagem metodológica de Foucault a partir de As palavras e as coisas." (MACHADO, Foucault, a ciência e o saber, p. 136).

${ }^{6}$ FOUCAULT, L’archéologie du savoir, p. 81.

${ }^{7}$ Cf. o capítulo "Arqueologia e história das ideias" em $A$ arqueologia do saber.

${ }^{8}$ FOUCAULT, L’archéologie du savoir, p. 265.
} 
possibilidades criadoras quase desenfreadas, o sujeito fundador torna-se alvo de uma interpretação da história que, ao descrevê-lo como elemento que elabora e impõe uma certa forma de se relacionar com os objetos, também o insere em um campo político que, apesar de não ser explicitamente assim denominado por Foucault na década de 60, anuncia um campo de análise daquilo que posteriormente será chamado por ele de poder.

Mas poder-se-ia dizer que a arqueologia se inscreve em algum campo de enunciados? Qual o estatuto desse discurso? A arqueologia enquanto discurso pertence à nova episteme que surge com o fim da episteme moderna, descrita no fim de Aspalavras e as coisas? Trata-se de questões que o próprio Foucault oportunamente esquivou-se quando perguntou a si mesmo, no fictício acerto de contas com o fenomenólogo no fim de $A$ arqueologia, sobre a natureza de seu ponto de vista'. Provavelmente ele era consciente dos paradoxos de seu projeto, e, quanto a esse problema, à arqueologia é possível estender a crítica que Nietzsche dirige a Kant no prólogo de Aurora, momento em que aponta para ambiguidade da posição "além-lógica (logisches Jenseits)" e carregada de um silencioso objetivo moral, de um tribunal que julga a si próprio ao determinar os limites da Vernunftland, ou, no caso de Foucault, de um discurso que determina o alcance possível dos discursos em cada episteme ${ }^{10}$. Apesar de Foucault negar que sua questão-guia assemelhe-se à crítica kantiana, pois não se trata de procurar a "legitimidade" ou o "direito" sobre a existência de um discurso", é possível afirmar que ambos os projetos filosóficos são convergentes na busca pela delimitação das fronteiras do pensamento, para além do problema da constituição da ciência ${ }^{12}$. O caráter prático do ponto de vista do arqueólogo torna-se aí um pouco mais evidente, e, para abordarmos a questão, é preciso investigar a crítica ao sujeito transcendental e suas consequências teóricas em As palavras e as coisas, para enfim oferecermos uma hipótese sobre os objetivos do projeto arqueológico. A busca pelo "impensado" que orienta a investigação proposta em As palavras e as coisas torna-a especialmente importante não apenas por ser uma obra relevante para compreendermos o modo como Foucault se insere no debate filosófico do seu tempo, mas também para esboçarmos respostas às perguntas realizadas acima. Afinal, a direção investigativa do arqueólogo não é o fato da razão e seus limites, e, mesmo que sua estrutura seja baseada na facticidade da história do pensamento, seu ponto de vista é sempre guiado pela possibilidade de transgressão das epistemes, que não são dadas como estáticas pois possuem espaços para deslocamentos e aberturas para um fora que deve ser buscado por quem deseja praticar um pensamento liberto da mediação das formas modernas do sujeito.

\footnotetext{
${ }^{9}$ FOUCAULT, L’archéologie du savoir, p. 267-268.

${ }^{10}$ NIETZSCHE, Werke, v. III, p. 6.

${ }^{11}$ FOUCAULT, L'archéologie du savoir, p. 251.

${ }^{12}$ Kant cria o conceito "arqueologia filosófica" para introduzir uma história a priori dos caminhos da metafísica até então como parte de uma investigação sobre o que diferencia seu estatuto com os das ciências que já obtiveram progressos consistentes: "Uma história filosófica da filosofia é em si mesma possível, não histórica ou empiricamente, mas racionalmente, isto é, a priori, embora estabeleça factos da razão, não os vai buscar à narrativa histórica, mas extrai-os da natureza da razão humana, como arqueologia filosófica.” (KANT, Os progressos da metafísica. p. 130). Aqui seria preciso examinar detalhadamente os paralelos possíveis entre as propostas dos dois autores, considerando principalmente as implicações desse texto de Kant. Sobre as aproximações entre Kant e a arqueologia de Foucault, cf. LEBRUN, "Notes sur la phénoménologie dans Les Mots et les Choses"; HAN, L'Ontologie manquée de Michel Foucault, entre l'bistorique et le transcendantal; PALTRINIERI, L'Expérience du concept, Michel Foucault entre épistémologie et histoire.
} 
Ao tratar do processo de formação dos discursos e do nascimento e estrutura dos conceitos filosóficos em $A$ arqueologia do saber Foucault apoia-se frequentemente em exemplos da história natural na Idade Clássica, período que se inicia no século XVII e prolonga-se até meados da Revolução Francesa. A descrição da história natural não deixa de ser um modelo para a hipótese foucaultiana de compreensão do funcionamento da episteme à qual pertence: um naturalista do século XVIII que pretendia classificar as espécies para organizar a natureza e conhecê-la de modo sistemático elaborava conexões entre as estruturas visíveis dos seres que pretendia equiparar, sistematizando os enunciados por meio de um conjunto de regras e criando, assim, "um conjunto de esquemas obrigatórios de dependências, de ordem e de sucessões onde se distribuem os elementos recorrentes que podem valer como conceitos" ${ }^{13}$. Essa forma de organizar a realidade por meio da multiplicação de signos é típica da episteme clássica e pode ser percebida também na gramática geral e na análise das riquezas: enunciados formulados em áreas distintas são retomados em um discurso a título de verdade admitida, de descrição exata, relacionando-se através de "formas de sucessão" e "formas de coexistência" ${ }^{\prime 4}$ entre elementos heterogêneos que são capazes de se relacionar por meio das semelhanças entre suas diferenças.

Na episteme da Idade Clássica, a condição de possibilidade do conhecimento não apenas dos seres vivos, mas dos objetos em geral, era subordinada à lógica de que o mundo existe independentemente da nossa interpretação, pois todo signo, para ser considerado um signo, deve expressar a relação que o conecta ao que ele significa, constituindo um sistema que $A$ lógica de Port-Royal resume da seguinte maneira: "Quando só se olha certo objeto como representando outro, a ideia que dele se tem é uma ideia de signo e esse primeiro objeto se chama signo" "15. Ou seja, para se tornar uma representação, o signo deve conter em si a própria relação de representação, em uma "organização estritamente binária" entre significante e significado. Não se trata, portanto, de uma concepção ternária de signo, organizada pela semelhança e dependente de uma interpretação que estabeleça essa ligação: nesse modelo de conhecimento a existência do mundo é provada pela capacidade do signo de duplicá-lo, formando uma ordem representativa que se equivale ao mundo por homologia. Abrem-se aqui dois reinos que se comunicam: as coisas do mundo estão presentes e os signos existem para representar essas coisas, ou seja, duplicar sua presença e torná-la acessível ao conhecimento através das ideias apresentadas na forma de signo. Em outros termos, havia uma identificação do Ser com a Ordem, que fundamentava a concepção de conhecimento como representação, ou seja, como um sistema de signos ${ }^{16}$.

Como toda ordem para existir deve necessariamente conter uma proporção entre elementos que se comunicam, seguindo os princípios da mathesis universalis, a representação

\footnotetext{
${ }^{13}$ FOUCAULT, Les mots et les choses, p. 76-77.

${ }^{14}$ FOUCAULT, L'archéologie du savoir, p. 74-78.

${ }^{15}$ FOUCAULT, Les mots et les choses, p. 78.

${ }^{16}$ Cf. FOUCAULT, Les mots et les choses, p. 65-68.
} 
de uma coisa necessariamente liga-se a outra representação, e justamente essa relação entre representações em suas devidas proporções que torna possível que uma representação represente a si mesma, em um processo reflexivo e infinito de reduplicação. $\mathrm{O}$ acesso ao mundo, portanto, é o acesso à ordem das representações. Nesse sentido, a constituição de um sistema da natureza é um processo de descrição em detalhes da estrutura dos seres vivos por meio da comparação entre as várias classes e a posterior disposição em classes mais específicas, gêneros, espécies e subespécies, etc., até que se atinja uma formação limite:

A estrutura, imitando e filtrando o visível, permite transcrever-se na linguagem. Por ela, a visibilidade do animal ou da planta passa por inteiro para o discurso que a escolhe. E talvez, em seu limite, ela própria restitui-se ao olhar através das palavras, como nesses caligramas botânicos com que sonhava Lineu ${ }^{17}$.

Por tal razão, por exemplo, não pode haver uma teoria da linguagem na Idade Clássica $^{18}$, pois uma teoria da significação não faria sentido em um mundo em que a significação não pode ser um problema: as coisas são dadas numa representação que já é por si só um signo, e o processo de criação do signo na consciência ou a própria produção e transformação, ao longo do tempo, de um fonema, partícula por definição não representativa, é algo que não pertence a esse sistema de pensamento. Como notado por Burgelin, "A linguagem-objeto é antípoda da língua bem feita (bien faite) de Condillac"19.

Ao contrário do objeto de conhecimento da episteme Moderna, que depende da mediação de um objeto específico - o homem -, para tornar-se possível, na era clássica as coisas do mundo se oferecem para serem conhecidas e são, por essência, cognoscíveis. Foucault tenta demonstrar isso recorrendo tanto a textos de filosofia (e várias filosofias podem ser parte da mesma episteme) quanto a três domínios do conhecimento empírico ou a formas de organização sistemática do mundo das coisas: gramática geral, história natural e análise da riqueza. Ao descrever a formação desses três discursos, ele reconstrói a lista de critérios, implícita na própria prática de domínios empíricos, que um objeto tem que cumprir para se tornar um objeto. Essa série complexa de regras que definem os tipos de objetos, conceitos, formas de "modalidades enunciativas" e "estratégias", que são possíveis apenas em um dado momento histórico e que qualificam algo como um objeto potencial de conhecimento, é o que Foucault denomina de episteme:

Por episteme entende-se o conjunto das relações que podem unir, a uma dada época, as práticas discursivas que dão lugar a figuras epistemológicas, a ciências, eventualmente a sistemas formalizados; o modo segundo o qual, em cada uma dessas formações discursivas, se situam e se realizam as passagens à epistemologização, à cientificidade, à formalização; a repartição desses limiares que podem coincidir, ser subordinados uns aos outros, ou estar defasados no tempo; as relações laterais que

\footnotetext{
${ }^{17}$ FOUCAULT, Les mots et les choses, p. 147.

${ }^{18}$ Cf. FOUCAULT, “O retorno da linguagem”, Les mots et les choses, p. 314-318.

${ }^{19}$ BURGELIN, L'archéologie du savoir, p. 853.
} 
podem existir entre figuras epistemológicas ou ciências, na medida em que se envolvem a práticas discursivas vizinhas mas distintas. A episteme (...) é o conjunto das relações que se pode descobrir, para uma época dada, entre as ciências, quando analisadas no nível das regularidades discursivas. ${ }^{20}$

Ao fazer falar os enunciados anônimos e puramente funcionais e relacionais da arqueologia, Foucault não nega o fato óbvio de que humanos têm um papel na criação dos saberes, como muito se confunde quando se critica esse ponto de vista filosófico; esse papel, no entanto, é limitado e especificado pelas "formações discursivas", um lugar pelos quais sujeitos falam e conhecem por motivos que se podem considerar determinantes. A formação discursiva, noção utilizada em $A$ arqueologia para denominar exatamente o que Foucault havia denominado de episteme em As palavras e as coisas, não é constituída pelo sujeito, mas cria um lugar pelos quais sujeitos falam e conhecem, sob o constrangimento dessa formação discursiva.

No entanto, entre os séculos XVIII e XIX, o aparecimento do homem, novo acontecimento "radical e que reparte por toda superfície do saber" 21 , reorganiza os modos como objetos eram conhecidos, e o modo de ser de coisas remanejaram-se de maneira tal que o conhecimento não pôde mais ser interpretado como representação. Para resumirmos, o problema na idade Moderna centraliza-se no fato de que uma representação deixa de ser uma duplicação do mundo para voltar-se para si, ou seja, ela passa a ser pensada como algo que é um efeito do sujeito e somente depois passa a ser uma representação que contém algo do mundo. $\mathrm{O}$ acontecimento da filosofia transcendental abre passagem para que as representações existam em determinadas condições formas a priori para alguém, e a capacidade representativa das representações é pensada então fora das representações mesmas, pois seria encontrada nas faculdades da razão desse novo sujeito. Então aparecem as questões que distinguem e modelam a modernidade: é este "sujeito" em si um objeto do mundo, como um animal que, talvez devido à configuração particular e especial da sua mente, possui essa capacidade discursiva de representar? Ou o sujeito é algo fora do mundo, irredutível a qualquer objeto em particular, já que é a própria condição do discurso sobre um objeto, como pensa Kant? Este é o dilema organizador da episteme moderna que gera, ao longo da divisão entre as estratégias empírica e transcendental, tanto o feixe de tendências positivistas quanto as várias correntes idealistas da filosofia moderna ${ }^{22}$.

Essa nova maneira de pensar os objetos torna possível que positividades conceituais como Vida, Trabalho e Linguagem apareçam e reorganizem as formações discursivas de novos saberes empíricos, que pouco remetem às configurações empíricas da episteme anterior. Esses objetos novos apenas surgem pela existência do duplo trato, pois são ao mesmo tempo positividades entre outras no mundo e condiçoes sob as quais essas coisas em geral podem se tornar objetos de representação. Os conceitos, portanto, não são representações autorreferentes, como na Idade Clássica, pois eles são ambos em si e sobre outra coisa, e aqui precisamos também nos lembrar de que, na medida em que os seres têm

${ }^{20}$ FOUCAULT, L'archéologie du savoir, p. 250.

${ }^{21}$ FOUCAULT, Les mots et les choses, p. 229.

${ }^{22}$ Cf. FOUCAULT, Les mots et les choses, p. 261-262. 
essa interioridade própria - uma espécie de profundidade existencial inacessível à representação -, eles são principalmente em si mesmos e, depois, secundariamente, relacionam-se ao mundo. Essa reflexão infinita da representação sobre si e posteriormente sobre o mundo é o que Foucault denomina de círculo antropológico, forma de humanismo que organiza a episteme moderna. "O homem" emerge não como objeto direto de qualquer ciência unificada, mas como efeito superficial da superposição dessas três empiricidades: o homem é aquele que

vive, fala e trabalha de acordo com as leis de uma economia, uma filologia e uma biologia, mas que também, por uma espécie de torção e sobreposição internas, adquiriu o direito, através da interação de essas mesmas leis, para conhecê-las e submetê-las a uma total esclarecimento ${ }^{23}$.

Conhecer a vida, a linguagem e o trabalho é, portanto, necessariamente uma operação direcionada para o dentro e para o fora, sendo tanto extrínseca à essência da figura do homem quanto algo que demanda um incessante retorno ao sujeito. O círculo antropológico insere o ato de conhecer e a figura do homem que está por trás dele como parte necessária de seu próprio domínio de investigação, pois o mapeamento da finitude humana é o que garante o saber seguro sobre a capacidade de alcance do mundo pelo sujeito de conhecimento. Ao mostrar o círculo autorreferente do duplo empírico-transcendental, Foucault aponta para a exclusão da diferença na episteme moderna, momento em que o "homem" passa a ser tanto fundamento quanto positividade de saberes que o determinam a partir de sua finitude:

De um extremo ao outro da experiência, a finitude responde a si mesma; ela é, na figura do Mesmo, a identidade e a diferença das positividades e de seu fundamento. Vê-se como a reflexão moderna, desde o primeiro esboço dessa analítica, inclina-se em direção a certo pensamento do Mesmo - em que a Diferença é a mesma coisa que a Identidade - exposição da representação, com sua realização em quadro, tal como o ordenava o saber clássico. (...) é aí que se verá sucessivamente o transcendental repetir o empírico, o cogito repetir o impensado, o retorno da origem repetir seu recuo. ${ }^{24}$

Temos, portanto, o problema da relação entre este sujeito transcendental puro desencarnado e aquele objeto particular que, ao mesmo tempo, somos. Assim, a modernidade ganha um objeto especial, ao contrário do que acontecia na episteme clássica: permanece entre os objetos um que parece especial, e até único, porque parece ter alguma relação íntima com a capacidade transcendental. O "homem" não é nem o sujeito puro da ciência, nem seu eventual objeto, ele é antes o fato de que ambos são, em algum sentido obscuro, um espelho um do outro. E, longe de ser uma solução, este é apenas o começo do problema que será trabalhado ao longo de todo o período da filosofia moderna.

${ }^{23}$ FOUCAULT, Les mots et les choses, p. 321.

${ }^{24}$ FOUCAULT, Les mots et les choses, p. 362. 
Foucault sublinha a necessidade de um pensamento alternativo ao paradigma do sujeito transcendental cuja finitude assume necessariamente a forma de uma antropologia e de uma demonstração da finidade que coincide com a descrição de regiões da experiência. Romper com o paradigma humanista é o objetivo da proposta de um novo pensamento, de caráter arqueológico ${ }^{25}$, que pretende identificar saberes as variantes relacionais aos quais ele pertence, fornecendo, assim, os meios para conceber a relatividade do conhecimento sem ter que atribuí-lo a qualquer sujeito ambíguo e determinante de significados, e viabilizando também formas de se pensar deslocamentos históricos que evitam a referência ao sujeito. Foucault fornece algumas pistas, ainda que timidamente, sobre a solução proposta pela arqueologia para escapar do duplo empírico-transcendental, entre elas, uma nova relação com a linguagem, de inspiração nietzschiana, esboçada em importante trecho de As palavras e as coisas:

É que estamos tão ofuscados pela recente evidência do homem que sequer guardamos em nossa lembrança o tempo, pouco distante, porém, onde existiam o mundo, sua ordem, os seres humanos, mas não o homem. Compreende-se o poder de abalo que pôde ter e que conserva ainda para nós o pensamento de Nietzsche, quando anunciou, sob a forma do acontecimento iminente, da Promessa-Ameaça, que logo o homem não seria mais, - mas sim o super-homem; este que, numa filosofia do Retorno, queria dizer que o homem, já desde muito tempo, havia desaparecido e não cessava de desaparecer, e que nosso pensamento moderno do homem, nossa solicitude para com ele, nosso humanismo dormiam serenamente sobre sua retumbante inexistência. Nós, que acreditamos estarmos ligados a uma finitude que só pertence a nós e que nos abre, pelo conhecer, a verdade do mundo, não deveria ser lembrado que estamos presos ao dorso de um tigre?26

Estar preso ao dorso do tigre é a imagem que Nietzsche utiliza no texto Sobre verdade e mentira no sentido extramoral ${ }^{7}$ para ilustrar a capacidade humana de se trancafiar numa cabine de vidro e enganar-se sobre sua origem natural, violenta e distante da nobreza idealizada pelos homens ao longo da história. Nietzsche refere-se, ao mencionar a imagem do tigre, à dificuldade imposta por um dilema em que qualquer uma das escolhas trará prejuízos: manter-se na ilusão da segurança da mentira ou descer do tigre e enfrentar a precariedade do cenário onde se encontra. Em seus sonhos, o homem está preso ao dorso do tigre, pois é

\footnotetext{
25 Sobre a experiência do impensado como "modo do pensar histórico", o qual trataremos na parte III deste artigo, cf. CANGUILHEM, “Mort de l'homme ou épuisement du cogito?”, pp. 603-604.

${ }^{26}$ FOUCAULT, Les mots et les choses, p. 333.

27 “O que sabe o homem, de fato, sobre si mesmo! Seria ele capaz de perceber-se inteiramente como se estivesse em uma iluminada cabine de vidro? (...) o homem repousa sobre o impiedoso, o voraz, o insaciável, o assassino, como se, em sonhos, estivesse dependurado sobre as costas de um tigre. Então de onde viria o impulso à verdade no mundo inteiro nessa constelação?” (NIETZSCHE, Sobre verdade e mentira em sentido extramoral, pp. 28-29).
} 
incapaz de olhar para sua própria condição e iniciar uma busca honesta pelas origens do seu "impulso à verdade". A referência de Foucault a Nietzsche em As palavras e as coisas faz o leitor se lembrar de que é preciso certa coragem, ou seja, uma postura coerente com certo padrão ético, para questionar o solo teórico do humanismo desenvolvido ao longo do século XIX, mesmo que seja o caso de abrir mão de crenças que sustentam algumas das ilusões do pensamento moderno.

Uma filosofia do Retorno dispensa o Homem como critério da representação e apresenta-nos outro esquema de leitura do mundo: o Retorno é um caminho para possibilitar um pensamento livre das mediações do sujeito, criando, assim, novas formas de interpretação sustentada pela diferença. Esse espaço aberto pelo pensamento libera o mundo para que as coisas "coincidam consigo mesmas". Para apresentarmos a questão dentro da filosofia de Nietzsche de forma breve, é preciso se lembrar de que o Retorno enquanto problema conceitual e linguístico é abordado por Nietzsche em Assim Falava Zaratustra, no capítulo "O convalescente". Pouco antes, no fim da segunda parte do livro, Zaratustra, após discursar para aleijados e mendigos sobre sua condição de vidente e ensinar que a "vontade é criadora" 28 e que essa "vontade de poder" está em lugar "mais alto que toda reconciliação", percebe que deve retornar à solidão para ter coragem de continuar a expressar seus pensamentos e despede-se dos amigos que o acompanhavam até então. Após o período solitário, Zaratustra anuncia parte de sua nova filosofia por meio de novas tábuas de valores e logo após retorna para sua caverna. Segue-se a primeira parte do capítulo "o convalescente" e Zaratustra é incapaz de cumprir sua inspiração e enfim trazer à tona o "pensamento abismal" 29 que aparece a ele nesse momento. Os traços substituem seu discurso e o recuo torna-se a maneira adequada e única de representar um pensamento, como um modo que Nietzsche encontra para expressar os limites da linguagem na tentativa de articular a experiência individual da escrita e seus limites conceituais. Zaratustra então desmaia de horror e desapontamento e encontra-se entre a vida e a morte por sete dias, mesmo período que Deus precisou para realizar a criação do mundo. Após acordar, o profeta depara-se com seus animais e os chama para o mundo, e a eles responde Zaratustra:

Como é agradável que existam sons e palavras: não são eles arco-íris e pontes aparentes entre aquilo que se acha eternamente separado? A cada alma corresponde outro mundo; para cada alma, cada outra alma é um mundo por trás. (...) Nomes e sons não foram dados às coisas para que o homem se reanime (erquicke) com as coisas? Bela tolice é a fala: com ela o homem dança por sobre todas as coisas ${ }^{30}$.

"Zaratustra", responderam os animais, "para os que pensam como nós, as próprias coisas dançam: vêm, dão-se as mãos, riem, fogem - e retornam. Tudo vem, tudo retorna;

\footnotetext{
${ }^{28}$ NIETZSCHE, Assim falou Zaratustra, p. 134.

${ }^{29}$ NIETZSCHE, Assim falou Zaratustra, p. 207.

${ }^{30}$ NIETZSCHE, Assim falou Zaratustra, p. 208.
} 
rola eternamente a roda do ser". Círculos metafóricos são apresentados pelos animais e o texto em seguida apresenta cada um dos anos da linha do tempo como igual a si mesmo, que todos os animais são iguais em si mesmos, e que Zaratustra é igual a ele mesmo. Os animais vinculam a última consequência dessa experiência individual a Zaratustra e enfatizam o 'eu', que é igualmente importante para esse pensamento e para a filosofia de Nietzsche. No entanto, trata-se de um ego originalmente diferenciado, cuja autorreferência mantém a possibilidade de repetição. Os animais, iniciados e representando as leis da natureza, atestam que seu processamento já começou e continuará no futuro. Nietzsche entrelaça os diferentes níveis de tempo e a pessoa de Zaratustra com seu pensamento, que assim se torna uma nova lei. A atenção está na própria pessoa, que é a porta da época, e cuja visão Nietzsche quer direcionar para a distância necessária para o pensamento do eterno retorno. $\mathrm{Na}$ "luxúria do futuro" está o poder que estimula o riso e o canto e permite a afirmação do destino. A queda de Zaratustra não termina apenas neste ponto, ela também começa novamente. Neste pensamento cíclico, não há começo nem fim e, no infinito contínuo, o "eu" retorna eternamente como um "nó de causas" e um destino necessário de cada um. O "eu" torna-se uma coisa que se repete como parte de uma causalidade: cada ser humano é um efeito do mundo causal que conecta a totalidade dos homens. Zaratustra reconhece suas próprias últimas palavras da boca dos animais com o silêncio. Ele retorna aos seus pensamentos, estabelecendo um sinal contra qualquer nova tentativa de objetivá-lo. Componente necessário desse pensamento, para satisfazê-lo afirmativamente, foi preciso distinguir a busca pela verdade da descoberta do pensamento, que emerge aqui como procedimento anterior. Uma nova função deve ser considerada, pela qual o "eu", fonte do significado e da novidade, substitui a verdade pela probabilidade.

A forma metafórica do pensamento de Nietzsche em Zaratustra inibe qualquer interpretação simples. No entanto, ao tomarmos como referência o comentário de Foucault mencionado acima, é possível sugerir que pensar o mundo como pensam os animais é o que recomenda Zaratustra para recolher o vir-a-ser: uma leitura possível do texto está na desconfiança na divisão entre o fato de que as coisas existem e a possibilidade de que elas possam ser entendidas pela linguagem, e Nietzsche critica justamente a mediação, através do homem, que força a inventar esse sujeito através da qual e para o qual tudo se torna significativo. Em certo sentido, para Foucault é preciso retomar o antigo jogo da episteme Clássica $^{31}$, e restabelecer a identidade entre o ser das coisas e a possibilidade de "dançar" sobre o mundo sem a necessidade da referência a ser um inteligível como a figura do homem.

O eterno retorno de todas as coisas é a experiência de um pensamento sem sujeito, que vivencia o mundo em sua singularidade e seu caráter experimental, sem a necessidade de um ato intrínseco da mente, que adiciona conteúdo ao mundo. Portanto, não se trata mais de uma mediação entre coisas e palavras, uma vez que o Retorno admite a singularidade de "cada alma", de cada diferença trazida pela singularidade do particular e de suas práticas, ele é correlato ao desaparecimento do homem. Quanto ao tema, ainda observa Deleuze: "Não compreendemos o eterno retorno enquanto não o opomos, de certa maneira, à identidade. O eterno retorno não é a permanência do mesmo (...) mas o retorno é ele mesmo o uno que

\footnotetext{
${ }^{31}$ Quanto à relação entre episteme Clássica e estruturalismo, cf. MANIGLIER, The order of things, p. 102-105.
} 
se diz tão somente do diverso e daquilo que difere." ${ }^{32}$ Ao invés de trocar o semelhante e de identificar o Mesmo em uma Representação, o Retorno dispensa a referência do homem ao fazer com que o vir-a-ser coincida consigo mesmo, se confirmando ao fazer as coisas retornarem sobre si mesmas, sem recorrer a leis, conceitos ou modelos. É desse modo que Nietzsche encontra a fórmula da afirmação do mesmo, permitindo que cada vida e suas perspectivas sejam auto-suficientes, e inaugurando, assim, uma nova maneira de pensar, que decreta também o fim e um novo começo para a filosofia, como nota Foucault:

Talvez se devesse ver o primeiro esforço desse desenraizamento da Antropologia ao qual, sem dúvida, está votado o pensamento contemporâneo, na experiência de Nietzsche (...) Com isso, Nietzsche, propondo-nos esse futuro, ao mesmo tempo como termo e como tarefa, marca o limiar a partir do qual a filosofia contemporânea pode recomeçar a pensar; ele continuará sem dúvida, por muito tempo, a orientar seu curso. Se a descoberta do Retorno é, realmente, o fim da filosofia, então o fim do homem é o retorno do começo da filosofia. Em nossos dias não se pode mais pensar senão no vazio do homem desaparecido. Pois esse vazio não escava uma carência; não prescreve uma lacuna a ser preenchida. Não é mais nem menos que o desdobrar de um espaço onde, enfim, é de novo possível pensar. ${ }^{33}$

Tal afirmação resume bem uma das intenções de um livro que apresenta um problema que Foucault enfrentou para finalmente praticar filosofia sem o auxílio do humanismo do círculo antropológico: suas genealogias a partir dos anos 70 não seriam uma tentativa de lidar com o fim da filosofia como praticada até a episteme moderna? E também não seriam o retorno do começo da filosofia, que agora segue o conselho dos animais de Zaratustra e libera as coisas para o pensamento sem a necessidade de relacioná-lo a um sujeito de conhecimento? Se As palavras e as coisas termina com um texto profético sobre uma nova era em que os discursos não serão sobre o homem mas sobre os discursos em si, as genealogias posteriores realizadas por Foucault são uma forma de discurso que leva em consideração a constituição de conhecimentos, discursos, domínios de objetos, etc., sem ter que se referenciar a um sujeito ou a um dispositivo transcendental que se relacionam ao campo de eventos que aparecem ao longo da história.

\section{III}

"E que se chamará de saber aquilo que é preciso arrancar da interioridade do conhecimento para ali recuperar o objeto de um querer, o fim de um desejo, o instrumento de uma dominação, a meta de uma luta" ${ }^{34}$. Feita a abertura genealógica para o campo do poder, o saber torna-se jogo da verdade liberto de sua suposta neutralidade após a interpretação do genealogista, ou, em outros termos, "o conhecimento liberado da relação

\footnotetext{
32 DELEUZE, Nietzsche et la philosophie, p. 53.

${ }^{33}$ FOUCAULT, Les mots et les choses, p. 333.

${ }^{34}$ FOUCAULT, Leçons sur la volonté de savoir, p. 18.
} 
sujeito-objeto" ${ }^{35}$. Ao pensar o conhecimento como um processo histórico, localizado em um plano de forças anterior à problemática da verdade e da relação sujeito-objeto, Foucault associa o universo dos signos a um "saber" produtor de esquemas que servem tanto à comunicação quanto a uma maneira de apoderar-se da multiplicidade para fins de acordo e dominação graças a um artifício ilusório da linguagem. O pensamento filosófico muitas vezes reforçou esse jogo de exclusões:

Quer seja, portanto, em uma filosofia do sujeito fundante, quer em uma filosofia da experiência originária ou em uma filosofia da mediação universal, o discurso nada mais é do que um jogo, de escritura, no primeiro caso, de leitura, no segundo, de troca, no terceiro, e essa troca, essa leitura e essa escrita não jamais põem em jogo senão os signos. O discurso se anula, assim, em sua realidade, colocando-se na ordem do significante. ${ }^{36}$

Filosofia do sujeito fundante, da experiência originária ou da mediação universal ${ }^{37}$, todas elas marcam, de alguma forma, o triunfo do signo, do Mesmo, um modo de representar um Diverso por meio de estruturas fixas, aplicando sobre elas a marca de uma força. Esse processo "anula" o discurso em sua realidade pois mascara sua fonte violenta: os discursos praticados ao longo da história são imanentes ao jogo de forças que exclui outras formas de discursos e assim age por coerção. Além disso, no plano genealógico, os discursos compõem os saberes como conjunto de enunciados necessariamente entrelaçados com o não-discursivo (ou seja, qualquer tipo de ação que não seja estruturada na produção de enunciados), e são modificados ao longo da história conforme a disposição das forças:

As práticas discursivas não são pura e simplesmente modos de fabricação de discursos. Elas tomam corpo em conjuntos técnicos, em instituições, em esquemas de comportamento, em tipos de transmissão e de difusão (...) que simultaneamente as impõem e as mantêm ${ }^{38}$.

A produção de discurso então passa a ser a uma prática também vinculada ao nascimento de técnicas, noção que, em Foucault, remete à criação de um mecanismo de atuação de um corpo sobre o outro tendo em vista a realização de certa estratégia da disposição das forças. Trata-se de consequência imediata da recusa foucaultiana em pensar um mundo teórico puro, uma vez que este é imanente ao mundo prático, ou, em outros termos, é causa e efeito das relações de poder. Ao deslocar o foco de sua crítica para as motivações práticas dos saberes, o genealogista nos aponta para o erro intelectual que subjaz a esta motivação: a crença de um fundamento puramente teórico na produção da verdade, independente do interesse prático, da relação entre os corpos, do diagrama das forças. É preciso que o signo seja disposto de maneira reconhecível para os outros, o que implica em

\footnotetext{
${ }^{35}$ FOUCAULT, Leçons sur la volonté de savoir, p. 205.

${ }^{36}$ FOUCAULT, $A$ ordem do discurso, p. 21.

${ }^{37}$ Foucault não explicita, mas é evidente sua crítica à fenomenologia e à ideia de uma consciência que se movimenta e assim é capaz de encaminhar as singularidades até o conceito, criando um discurso que repercute uma verdade.

${ }^{38}$ FOUCAULT, Leçons sur la volonté de savoir, p. 217.
} 
deformações para que determinada força se conserve e persevere. Nesse sentido, o saber funciona como uma técnica que assegura a conservação de uma força que domina:

A transformação de uma prática discursiva está ligada a todo um conjunto, frequentemente muito complexo, de modificações que podem dar-se tanto fora dela (nas formas de produção, nas relações sociais, nas instituições políticas) como nela (nas técnicas de determinação dos objetos, no afinamento e ajuste dos conceitos, no ajuste dos conceitos, no acúmulo de informação) ou ao seu lado (em outras práticas discursivas). E está ligada a elas no modo não de um simples resultado, e sim de um efeito que detém ao mesmo tempo sua própria autonomia e um conjunto de funções precisas com relação ao que a determina. ${ }^{39}$

As mudanças que ocorrem nas práticas discursivas não indicam uma história de desenvolvimento ou a marca de sua continuidade; ao contrário, suas mudanças são efeitos de uma causa imanente a elas: há correlação, pressuposição recíproca entre a causa e o efeito, entre a emergência irregular das forças e suas formalizações. Se os efeitos atualizam e as modificam é porque as relações de forças ou são apenas virtuais, potenciais, instáveis, e definem apenas possibilidades e probabilidades de interação enquanto não integram num conjunto capaz de dar forma ao seu sentido e à sua função. Essa atualização também é uma integração, um conjunto de integrações progressivas, originadas em diferentes locais ("fora dela", "nela", "ao seu lado"), que tendem para a dominação, operando assim um alinhamento, uma homogeneização, uma soma de relações de força. Vejamos, por exemplo, como Foucault inicia seu curso de 1978 no Collège de France esclarecendo essa questão:

Os mecanismos de poder são parte intrínseca de todas essas relações, são circularmente o efeito e a causa delas, mesmo que, é claro, entre os diferentes mecanismos de poder que podemos encontrar nas relações de produção, nas relações familiares, nas relações sexuais, seja possível encontrar coordenações laterais, subordinações hierárquicas, isomorfismos, identidades ou analogias técnicas, efeitos encadeados que permitem percorrer de uma maneira ao mesmo tempo lógica, coerente e válida o conjunto dos mecanismos de poder e apreendê-los no que podem ter de específico num momento dado, durante um período dado, num campo dado. 40

O comentário de Deleuze sobre a relação de imanência entre os campos do poder e do saber ilumina esse problema pela leitura da função-panóptico: nessa disposição de relação de poder, trata-se de revelar um modo de "impor uma conduta qualquer a uma multiplicidade humana qualquer." ${ }^{41}$. O poder disciplinar, como qualquer outra forma de poder, opera enquadramentos do tipo "matéria-função" por todo campo social, atravessa e aplica-se, distintivamente, a duas formas de multiplicidade: à "matéria visível" (escolas, hospitais,

${ }^{39}$ FOUCAULT, Leçons sur la volonté de savoir, p. 218.

${ }^{40}$ FOUCAULT, Segurança, território, população, p. 4-5

${ }^{41}$ DELEUZE, Foucault, p. 43. 
prisões, etc.), e às "funções enunciáveis", ou seja, aos conteúdos dos saberes. A implementação e a manutenção dessas formalizações se dá sempre por meio de técnicas: "técnica de governo", "técnica dos dispositivos", "tecnologias de poder" são exemplos de termos que, no âmbito do pensamento de Foucault, não se resumem à criação e ao uso de uma máquina ou instrumento, mas equiparam-se e remetem sempre a um mesmo processo, a um ato de um corpo sobre o outro, ato que possui uma eficácia e que se propaga entre os corpos por sempre se direcionar para um determinado fim, sendo estrategicamente capaz de alcançá-lo. Nesse sentido, tanto ações como as práticas de si na Antiguidade quanto as saberes estatísticos utilizados para o governo das populações ou o modelo do panóptico serão considerados técnicas, uma vez que são criados no âmbito de uma relação de forças e utilizados para um determinado fim, ou seja, compõem parte da estratégia de uma força que domina.

Dessa maneira, a partir da análise das mutações que o poder impõe sobre "o visível e o enunciado", Foucault expõe as peças dos jogos das relações de forças que constituem as relações de poder. Esse campo de forças é constituído de singularidades instáveis e violentas, não havendo, assim, nem distribuição estável de forças, nem configurações privilegiadas. $O$ poder "age como uma causa imanente não-unificadora" pois jamais é qualificada como uma substância: "Ele duplica a história com um devir"

A partir do exposto ao longo do artigo, notamos um filósofo que, ao desenvolver um método arqueológico, aponta, por um lado, para a necessidade de estabelecer o limiar de existência dos discursos e o corte que demarca o que é possível dizer em determinado momento da história, e, por outro, para a crítica de certo modo hegemônico do pensamento como uma forma de exercício do poder centralizado em certos paradigmas da representação. A arqueologia é um método criado para análise de relações entre discursos em sua existência própria, tornando possível analisá-los sem referências a atividades centradas em um sujeito que, na modernidade, torna-se fonte de significados e finalidades históricas. É na arqueologia também que se encontra os fundamentos práticos para uma futura proposta genealógica de uma dissolução dessa unidade por meio de uma análise dos campos de relações de força nos quais formas de saber e técnicas de poder articulam-se para potencializar um estado de forças. A arqueologia, portanto, pode ser definida uma prática histórico-filosófica que investiga os múltiplos e instáveis processos de eliminação e de seleção de saberes que determinam objetividades em função de estratégias localizadas em um diagrama de relações de enunciados, de modo que um de seus objetivos é abrir um domínio indispensável para que os enunciados contidos nesses saberes deixem de ser descritos como simples reprodução dos esquemas internos de uma forma de conhecimento.

\section{THE ARCHEOLOGY AND POLITICS OF ANTIHUMANISM}

${ }^{42}$ DELEUZE, Foucault, p. 45. 
Abstract: The article proposes to interpret Archeology as a practice by analyzing it as a method that aims not only to circumscribe the discursive fields that make possible the knowledge of each time, but also to define what, at its extreme limit, is thinkable. For Foucault it was essential to make possible the "unthinkable" through the experience of difference. We intend to identify in Foucault this movement of thought, which a certain academic tradition has identified as "anti-humanism" theorists, by describing the anthropological circle that characterizes the modern episteme in "The order of things", Foucault's consequent critique of this problem and his later solution in texts that begin his genealogical course.

Keywords: Foucault - Archeology - practice - representation - humanism.

\section{REFERÊNCIAS BIBLIOGRÁFICAS}

BURGELIN, P. “L'archéologie du savoir”. In: Esprit, n 5, 1967, pp. 843-886.

CANGUILHEM, G. "Mort de l'homme ou épuisement du cogito?". In: Critique, n 24, 1967, pp. 599-618.

DELEUZE, G. Foucault. Tradução de Claudia Martins. São Paulo: Ed. Brasiliense, 2005.

Nietzsche et la philosophie. Paris: Presses universitaires de France, 1962.

FOUCAULT, M. Naissance de la clinique. Paris: Presses Universitaires de France, 1963.

Les mots e les choses Paris: Éditions Gallimard, 1966.

L'archéologie du savoir. Paris: Tel Gallimard, 1969.

L'ordre du discours: Leçon inaugurale an Collège de France. Paris: Gallimard, 1971.

Dits et écrits I. 1954-1969. Paris: Éditions Gallimard, 1994.

Segurança, território, população. Curso no Collège de France (1977-1978). Tradução de Eduardo

Brandão. São Paulo: Martins Fontes, 2008.

HAN, B. L'Ontologie manquée de Michel Foucault, entre l'bistorique et le transcendantal. Grenoble, Jérôme Million, 1998, pp. 66-117.

KANT. Os progressos da metafísica. Tradução de Artur Morão. Lisboa: edições 70, 1995.

LEBRUN, G. "Notes sur la phénoménologie dans Les Mots et les Choses". In: Michel Foucault, philosophe, Rencontre internationale, Paris, 9, 10, 11 janvier 1988, Paris, Seuil, Des Travaux, 1989, pp. 33-53.

MACHADO, R. Ciência e Saber: a trajetória da arqueologia de Michel Foucault. Rio de Janeiro: Zahar, 2005.

Foucault, a ciência e o saber. $3^{\text {a }}$ ed. Rio de Janeiro: Zahar, 2006.

MANIGLIER, P. The order of things. In: A companion to Foucault. New York, NY: Wiley-Blackwell, 2013. pp. 104-121. 
NIETZSCHE. Werke. Berlin: Walter de Gruyer \& Co, 1968.

. Sobre verdade e mentira no sentido extramoral. Tradução de Fernando de M. Barros. São Paulo: Hedra, 2008.

. Assim falou Zaratustra. Tradução de Paulo César de Souza. São Paulo: Companhia das letras, 2011.

PALTRINIERI, L. L'Expérience du concept, Michel Foucault entre épistémologie et histoire. Paris: P.U.S., 2012, pp. 120-144. 